\title{
Evaluation of sludge-based carbon as packing material in biofiltration in comparison to classic materials
}

\author{
A. D. Dorado*, J. Hernández**, G. Ribera*, D. Gabriel **, J. Lafuente** and X. Gamisans* ${ }^{\dagger}$ \\ *Department of Mining Engineering and Natural Resources, Universitat Politècnica de Catalunya, Bases de \\ Manresa 61-73, 08240 Manresa, Spain \\ **Department of Chemical Engineering, Universitat Autònoma de Barcelona, Edifici C, 08193 Bellaterra, \\ Barcelona, Spain \\ † Corresponding author E-mail: xavierg@emrn.upc.edu
}

\begin{abstract}
The main objective of this study is to determine the most rellevant characteristics and physical behaviour of carbon obtained from sludge (SBC) from wastewater treatment facilities and to use it as support material in a biofilter in comparison to classic materials commonly used in this purpose. Materials for comparison were selected according to previous works in the field of biofiltration including organic and inorganic (or synthetic) materials. Results obtained demonstrate that SBC is an acceptable packing material according to the main parameters to be valued in any biofilter: nutrients supply capability, high water retentivity, high adsorption capacity, to provide low pressure drop, allow for biomass attachment or a commitment among them. The study includes the performance of SBC in an operative, lab-scale biofilter besides the characterization of the adsorption capacity and pressure drop as a function of operational parameters.

Keywords: biofiltration; packing materials; sludge-based carbon
\end{abstract}

\section{INTRODUCTION}

Biological treatments have become an effective and economical alternative to traditional systems for waste gases treatment. However, different packing materials have been used in biofiltration without a global agreement about which ones are the most adequate to support the biomass. A number of works published by different research groups have shown that the packing material selected may influence the performance of bioreactors to a great extent (Kennes et al. 2001). Then, it is obvious that proper packing material selection is a vital factor to be considered if high performance and stability of the bioreactor are desired. Additionally, the excess of sludge produced at wastewater treatment plants is a general problem that needs to be addressed by means of original solutions. The conversion of biological sludge into carbon and its subsequent usage as packing material in bioreactors could lead to a highly cost-effective and environmental-friendly way of taking advantage of this material.

The nature of the packing material is a fundamental factor for successful application of biofilters because it affects the frequency at which the medium is replaced and other key factors such as bacterial activity and pressure drop across the bioreactor (Devinny et al. 1999). Among the naturals carriers reported, compost, peat, soil and wood derivatives are the most extensively used while GAC, perlite, glass beads, ceramic rings, polyurethane foam, polystyrene and vermiculite are some of the several synthetic or inert carriers which have been studied (Kennes et al. 2001). Specific surface area, porosity, density, water retention capacity and the nutrients availability are some of the most important characteristics of the filter media (Janni et al. 2001).

The effects of adsorption on biofilter performance are complex, depending on the medium, contaminant and microorganisms (Alexander 1994). The adsorption capacity of the medium tends to smooth changes in concentrations and to reduce stress on the microbial population. A rapid desorption may keep the microorganisms healthy and degradation rates high when concentrations 
are falling and reduce toxic shocks when concentrations rise (Devinny et al. 1999). It has been reported that fluctuations between 0 and $1000 \mathrm{mg}$ toluene $\mathrm{m}^{-3}$ are decreased to a value of about 300 $\mathrm{mg} \mathrm{m}{ }^{-3}$, which is subsequently completely degraded in a biofilter (Weber et al. 1995). Otherwise, pressure drop is an important parameter due to the inherent air flowing through the bed economical cost. Moreover, the progressive bed compactation, if not detected properly, might cause a plant failure and the consequent packing substitution (Delhoménie et al. 2003).

In the work presented herein, a comprehensive study of the advantages and drawbacks of SBC as packing material in biofiltration has been performed in comparison to classic support media commonly used on this purpose. Classic packing materials selected for the comparative study include a group of 4 organic materials (coconut fibre, pine leaves, peat with heather and compost from a waste water treatment plant) and 4 inorganic or synthetic materials (polyurethane foam, lava rock, an immature -lignite- coal and a synthetic material based on a thin compost layer over a claymade particle). Moreover, a comparative study of commercial activated carbon, coal from a natural source and SBC is included. Sorption data have been obtained generating breakthrough curves by increasing the initial VOC load according the staircase method. Data have been used to estimate model parameters of Langmuir and Freundlich equations in order to know the maximum adsorption capacities of materials and the affinity between them and the pollutant. An in-deep pressure drop characterization study is also performed by relating the effect of the main parameters as bed porosity, gas superficial velocity and water content circulating through the material media. Finally, suitability of SBC as support media is tested in a lab scale biofilter to abate a continuous toluene load.

\section{MATERIALS AND METHODS}

\section{Packing materials}

Sludge-based carbon (SBC) was provided by the Department of Civil and Environmental Engineering, Imperial College, London. Material was studied and compared to a total of 9 common packing materials used in biofiltration by determining their main physico-schemical properties. Organic packing materials analysed were coconut fibre, pine leaves, peat with heather and compost from sludge of a waste-water treatment plant. The inorganic or synthetic packing materials studied were polyurethane foam, lignite from Mequinenza mines (Spain), lava rock, commercial activated carbon (Chemviron) and an advanced material based on a thin layer of compost over a clay pellet.

\section{Analytical methods}

Characterization of packing materials was carried out according to standard methods (TMECC, 2002). The following properties were compared in each case: specific surface area, elementary analysis, extractable phosphor content, organic matter, humidity, water holding capacity, retentivity, ph, conductivity and buffer capacity of the leachate. Specific surface area and material density were determined by the BET technique in a Micromeritics, model Tristar 3000, apparatus. Elementary analysis was realised by combustion in standard conditions using sulphanilamide as standard (EA1108 ThermoFisher Scientific). Extractable phosphor was determined by the technique of ICP in a multichannel analyser in standard conditions (Thermo Jarell-Ash model 61E Polyscan) using Baker Instra as digester of the sample.

\section{Experimental setup}

Pressure drop assessment experiments were carried out using a lab-scale plant consisting of a PVC column with an inner diameter of $4.6 \mathrm{~cm}$ and a height of $70 \mathrm{~cm}$. Synthetic air was conducted by 2 different circuits. In the former, the air stream was passed through a water column in order to 
increase the relative humidity and in the latter; the air stream arrived completely dry to the fixed bed. The inlet air pressure and the flow rate were controlled and measured by means of a pressure regulator (Norgren Excelon) and a flowmeter (Tecfluid 2100) respectively. Throughout this study, the gaseous stream was supplied in up-flow mode. Tap water was sprinkled continuously at the top of the fixed bed be means of a peristaltic pump (Magdos LT-10) and the water content was measured by an optical level sensor. Pressure drop was determined by means of two digital differential pressure meter used according to the range and detection limit required (Testo 51220hPa and Testo 506-200 hPa).

For the sorption assessment experiments the inlet pollutant concentration was achieved dispensing toluene (Panreac 99.5\%) by means of an automatic burette (Crison 2S-D) at different volumes and injection frequencies. The air flow was controlled and measured by a mass flow controller (Bronhorst F-201CV). Toluene concentration was measured by an on-line photo ionization detector (Photovac 2020) placed at the inlet and outlet of the bed and connected to a computer for continuous data collection. Inlet toluene concentrations to evaluate the quantity adsorbed in materials were selected according to common VOC's concentration treated by biofiltration (between 100 and $1000 \mathrm{ppm}$ ) (Deviny et al. 1999). Studied support materials were previously sterilized using sodium azide (Sharlau) in a $10 \%(\mathrm{w} / \mathrm{w})$ ratio to remove the interferences of biological activity in the adsorption measurements (Pagans et al. 2006).

Study of toluene abatement was carried out using a lab-scale plant consisting of a PVC column with an inner diameter of $8.6 \mathrm{~cm}$ and a height of $90 \mathrm{~cm}$. Reactor was packed with $\mathrm{SBC}$ mixed with coconut fiber $(1: 1, \mathrm{v}: \mathrm{v})$ to a height of $50 \mathrm{~cm}$ meaning a total bed volume of $2.9 \mathrm{~L}$ each one. The biofilter was inoculated with 1 liter of activated sludge from an urban wastewater treatment plant

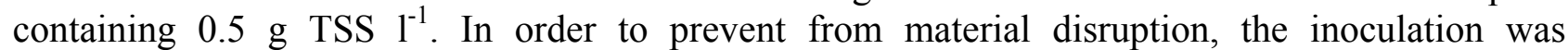
performed by submerging the SBC in this culture for $28 \mathrm{~h}$. The air stream passed through two water columns in series in order to increase the inlet air relative humidity up to $90 \%$. The gas flow rate was kept at $425 \mathrm{~L} \mathrm{~h}^{-1}$, corresponding to an EBRT of $25 \mathrm{~s}$. Gas samples were collected from sampling ports at the inlet and outlet of the reactor by means of Tedlar ${ }^{\circledR}$ bags. Toluene concentration was measured in triplicate using a gas chromatograph (series 6890N GC, Agilent Technologies) equipped with a capillary column (HP-5, Agilent technologies) and a flame ionization detector (FID).

\section{RESULTS AND DISCUSSION}

\section{Characterization of packing materials}

Elementary analyses were performed to distinguish the capacities of the material to provide nutrients to the immobilized microorganisms. Water retentivity and water holding capacities were determined to identify the capacity of the materials to keep optimal conditions for the activity of the microorganisms and to gain knowledge about the frequency of watering periods. Moreover, buffer capacities were assessed to establish the capability of each material to cope with $\mathrm{pH}$ changes due to the microorganism's metabolic activity. Finally, specific surfaces were also determined. Results are summarized in Table 1 and 2 for all the materials tested.

High nutrient, (i.e. phosphorous, potassium and sulphate contents), and trace elements, are required for the establishment of a dense process culture. Most natural organic media have enough nutrients for most biofilter conditions without the necessity of supplements (Bohn 1996). Regarding to the elementary composition of packing materials (Table 1), SBC is the material with the highest content in nitrogen and phosphorus (3.4\% and $6.6 \%$, respectively) but depending on the speciation, they 
are not equally available for microorganisms. Compost is the organic material which the highest content in nutrients $(2.7 \%$ in nitrogen and $1.4 \%$ in phosphorous). It must be pointed out that the immature coal (lignite) studied showed a significant concentration of sulphur $(8.8 \%)$ which is related to the quality of the material. Also, the presence of sulphur has been detected in compost, conversely to SBC. Among the organic materials analysed, coconut fibre and pine leaves present the highest organic matter content. The high organic matter content detected in coals is a reflex of the immature nature of these materials.

Table 1. Elementary composition of sludge-based carbon and classic packing materials

\begin{tabular}{lcccccc}
\hline & Nitrogen (\%) & Carbon (\%) & Hydrogen (\%) & Sulphur (\%) & $\begin{array}{c}\text { Phosphorus } \\
\text { (\%) }\end{array}$ & $\begin{array}{c}\text { Mineral matter } \\
\text { (\%) }\end{array}$ \\
\hline Sludge-based carbon & 3.39 & 38.54 & 0.49 & 0.00 & 6.60 & 54.56 \\
Activated carbon & 0.47 & 85.81 & 0.62 & 0.26 & 0.04 & 14.42 \\
Compost & 2.68 & 33.86 & 4.63 & 0.63 & 1.45 & 46.44 \\
Peat with heather & 1.26 & 21.99 & 2.56 & 0.15 & 0.05 & 33.77 \\
Coconut fiber & 1.17 & 45.05 & 6.18 & 0.12 & 0.03 & 8.38 \\
Advanced material & 0.34 & 2.45 & 0.18 & 0.19 & 0.13 & 97.43 \\
Lava rock & 0.00 & 0.40 & 0.00 & 0.00 & 0.18 & 99.37 \\
Pine leaves & 0.56 & 45.18 & 6.10 & 0.05 & 0.02 & 13.29 \\
Lignite & 0.85 & 44.37 & 4.06 & 8.81 & 0.00 & 20.31 \\
Polyeurethane foam & - & - & - & - & - & - \\
\hline
\end{tabular}

Table 2. Physical characteristics and leachate properties of SBC and classic packing materials

\begin{tabular}{lcccccc}
\hline & $\begin{array}{c}\text { Surface area } \\
\left(\mathrm{m}^{2} \mathrm{~g}^{-1}\right)\end{array}$ & $\begin{array}{c}\text { Water holding } \\
\text { capacity }\left(\mathrm{g} \cdot \mathrm{g}^{-1}\right)\end{array}$ & $\begin{array}{c}\text { Water retentivity } \\
(\% \text { dia }\end{array}$
\end{tabular}

The optimal moisture content for microbial activity is very close to the media's water holding capacity (Bohn 1996). In general, it is desirable to have media with a high water-holding capacity. Organic media are 40 to $80 \%$ water (by weight) when they are saturated (Devinny et al. 1999). Packing materials studied keep a water holding capacity inside the typical interval, being in the higher values for coconut fibre, pine leaves and peat (Table 2). Among the inorganic or synthetic support media, SBC and activated carbon kept a high water holding capacity. However, the low water holding capacities of SBC and activated carbon analysed in comparison to organic materials are compensated by the high water retentivity capacities (around $-17 \% \cdot$ day $^{-1}$ ).

Regarding to the specific surface, as expected, commercial activated carbon is the support media with the highest area value $\left(950 \mathrm{~m}^{2} \cdot \mathrm{g}^{-1}\right.$. However, SBC increase the surface area in an order of magnitude in comparison to classic packing materials studied (around $90 \mathrm{~m}^{2} \mathrm{~g}^{-1}$ ). Thus, SBC and activated carbon appears to be advantageous for adsorbing pulse loads of pollutant. 
Leachate properties of packing materials studied show a $\mathrm{pH}$ close to the neutrality or slightly acid ( $\mathrm{pH} \approx 5$ for peat) and a buffer capacity inferior to $150 \mathrm{ml} \mathrm{SO}_{4}{ }^{2-} 1^{-1}$ in all the cases. On the contrary, $\mathrm{SBC}$ shows the most basic $\mathrm{pH}$ in the leachate (superior to $\mathrm{pH}=8$ ). Leachate conductivity of the materials was similar among them (excepting for inorganic materials), being $470 \mu \mathrm{S}$ the highest value determined in compost.

Taking the results of physical characterization into account and considering especially the high nutrients content, surface contact and water retentivity, the most suitable organic material to support the biomass in a biofilter is probably compost. However, SBC shows a higher surface contact area and water retentivity, keeping high levels of nutrients content and clean drainage water which predicts a notable behaviour of the material as support media. In order to complete the study and evaluate the feasibility of SBC as packing material, adsorption capacity tests and pressure drop were compared for both pre-selected materials.

\section{Sorption capacity characterization form dry and wetted packing materials}

Sorption capacity is determined for both dry and wet materials to obtain information regarding to the interactions nature between the contaminant, packing materials and the aqueous phase. Toluene adsorptions on packing materials are evaluated by a frontal analysis based on toluene measurement at the inlet and outlet of a fixed-bed according to the staircase method (Vente et al. 2005). Isotherms are determined from the breakthrough times of step changes in the feed concentration. Adsorption capacities were evaluated for toluene on compost and SBC.

The experimental quantities of the toluene adsorbed are presented in figure 1 for compost and SBC, respectively. In both cases, the behaviours of the materials are analysed in dry and wet conditions. Adsorption capacities of dry materials are evaluated to describe the behaviour in the non-colonized patches in an operated biofilter or to characterize the use of the materials as a buffer to adsorb intermittent pollutant loads using the material previously to the inlet of a biofilter. Adsorption capacities of wet material describe the ability to absorb intermittent pollutant loads when the media supports are used in steady conditions.
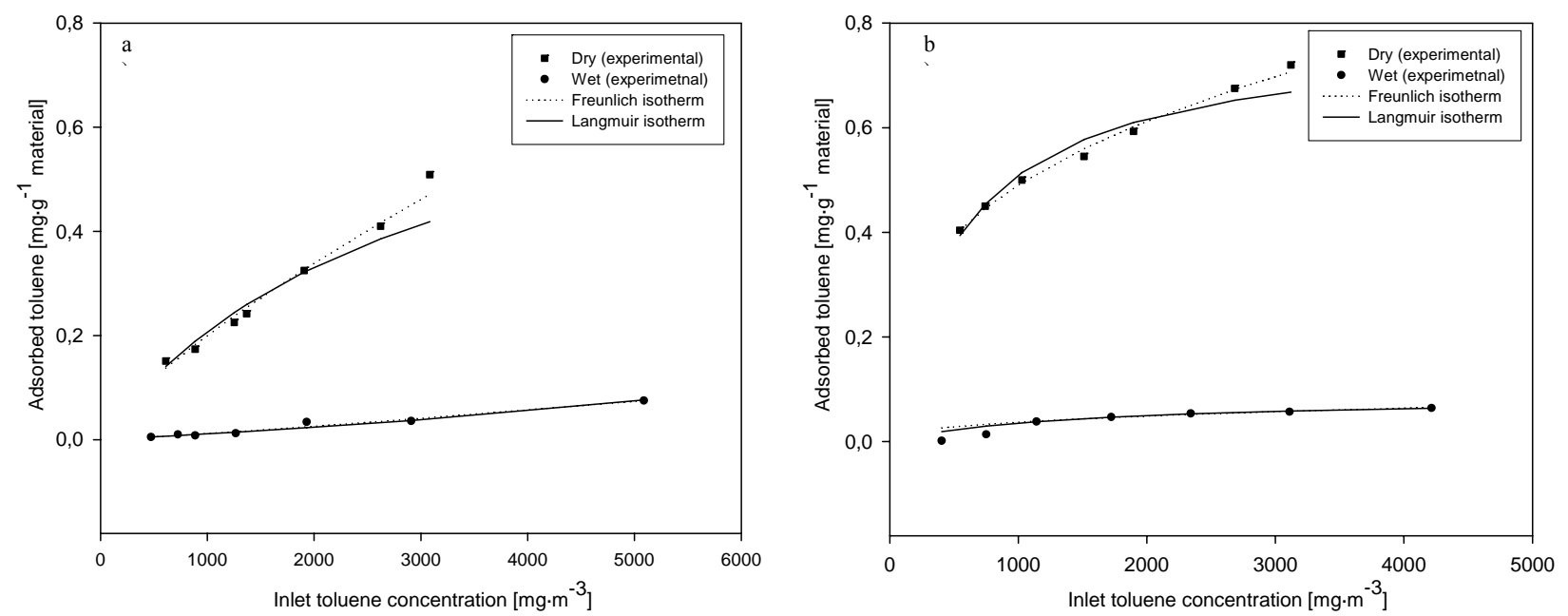

Figure 1. Adsorption isotherms (experimental, Langmuir, and Freundlich) of toluene on compost (a) and SBC (b).

In figure 1, experimental quantities of toluene adsorbed on both porous materials at $22^{\circ} \mathrm{C}$ in dry and wet conditions are fitted to the well-known isotherms of Freundlich (dashed line) and Langmuir 
(solid line). Characteristic parameters of the mentioned equations were obtained by non-linear regression of the experimental data.

Freundlich isotherms are obtained assuming that the energy of interaction between pollutant and adsorbent material is distributed on the surface, grouping into one patch those having the same adsorption energy. On each patch, a pollutant molecule only adsorbs onto only one adsorption site of the material (Do 1998). On the contrary, the Langmuir model assumes that the surface is homogenous, thus, the energy of interaction between pollutant and adsorbent material is constant over all sites. The adsorption on surface is localised, so each site can accommodate only one molecule (Ruthven, 1984).

Freundlich equation (Eq. 1), popularly used in gas phase systems having heterogeneous surfaces, is one of the earliest empirical equations used to describe equilibria data. Langmuir equation (Eq. 2) is the simplest theoretical model for monolayer adsorption.

$$
\begin{array}{ll}
q=K_{f} \cdot C_{i n}{ }^{n} & \text { Eq. } 1 \\
q=K_{1} \cdot \frac{C_{i n}}{K_{2}+C_{i n}} & \text { Eq. } 2
\end{array}
$$

where $\mathrm{q}$ is the concentration of the adsorbed specie in the material in $\mathrm{mg} \mathrm{g}^{-1}$ of bed; $\mathrm{K}_{\mathrm{f}}$ is the first Freundlich parameter in $\mathrm{m}^{3} \mathrm{~g}^{-1} ; \mathrm{C}_{\text {in }}$ is the inlet concentration of the specie in the gas phase in $\mathrm{mg}$ $\mathrm{m}^{-3} ; \mathrm{n}$ is the second Freundlich parameter; $\mathrm{K}_{1}$ is the maximum adsorbed capacity of the material in $\mathrm{mg} \mathrm{g}^{-1}$ and $\mathrm{K}_{2}$ is the inverse adsorption equilibrium constant in $\mathrm{mg} \mathrm{m}^{-3}$.

In the interval of toluene concentration studied, adsorption capacities of SBC are higher than the quantity of pollutant adsorbed on compost, being twice at high gas-phase concentrations and increasing the capacities up to six times in low concentrations. The higher adsorption capacity of $\mathrm{SBC}$ is in part explained by the high surface area detected in the characterization of materials in comparison to compost (table 1).

The most relevant observation in figure 1 is how the adsorption capacities for both materials decrease drastically when materials are in wet conditions. The water film on materials represents a high resistance for the mass transfer of a hydrophobic compound as toluene. Thus, pollutant concentrations on the liquid-solid interface of wet materials are lower than the concentrations on the gas-solid interface in dry conditions. As liquid-phase diffusion is much slower than gas-phase diffusion, the toluene is hardly adsorbed at short contact times. Moreover, previous works affirms that water compete for adsorptive sites when a biofilter is put into operation (Loy et al. 1997). Present results show that the advantages of materials with high adsorption capacity in biofiltration disappear when materials are completely wet. However, using a separate carbon column placed before a biofilter, the presence of water is prevented and a stable pollutant concentration is buffered to degrade in the biofilter.

Discussion from figure 1 is in concordance with the thermodynamic and kinetic interpretation of estimated parameters for Freundlich equations and Langmuir model which are presented in table 3. Regarding Freundlich parameters, estimated values of $\mathrm{n}$ are lower in SBC than in compost, that is the adsorption isotherm behaviour deviates further away from the linear isotherm, so it is approaching a rectangular isotherm or irreversible isotherm. The concentration needs to go down to an extremely low value before adsorbate molecules desorb from the surface. The value of this 
parameter, related to the affinity between pollutant and material, is similar in each material independently of the water presence.

Table 3. Parameters of the Freundlich and Langmuir isotherm for compost and SBC.

\begin{tabular}{lccccc}
\hline & & \multicolumn{2}{c}{ Compost } & \multicolumn{2}{c}{ Sludge-based carbon } \\
& & Dry material & Wet material & Dry material & Wet material \\
\hline \multirow{3}{*}{ Freundlich } & $\mathrm{K}_{\mathrm{f}}\left(\mathrm{m}^{3} \cdot \mathrm{g}^{-1}\right)$ & 0.0006 & 0.000006 & 0.0514 & 0.0161 \\
& $\mathrm{n}$ & 0.83 & 1.11 & 0.33 & 0.31 \\
& $\mathrm{fval}$ & 0.0369 & 0.0108 & 0.0227 & 0.0216 \\
\hline \multirow{3}{*}{ Langmuir } & $\mathrm{K}_{1}\left(\mathrm{mg} \cdot \mathrm{g}^{-1}\right)$ & 2.10 & 0.19 & 0.83 & 0.24 \\
& $\mathrm{~K}_{2}\left(\mathrm{mg} \cdot \mathrm{m}^{-3}\right)$ & 10000 & 10303 & 655 & 659 \\
& $\mathrm{fval}$ & 0.0450 & 0.0183 & 0.0616 & 0.0008 \\
\hline
\end{tabular}

Results presented in table 3 for Langmuir data fitting, show that the affinity between pollutant and material $\left(\mathrm{K}_{2}\right.$ value) is more important in SBC than in compost but it is independent on whether the material is wet or dry, in concordance with the interpretation of Freundlich parameters. Regarding the value of $\mathrm{K}_{1}$, which is related to the maximum adsorption capacity of the material, it is higher in compost than in SBC.

\section{Operational parameters influence on pressure drop}

Considering that the adsorption capacities of pre-selected materials are similar under the typical operating conditions of biofilters, i.e. with a certain amount of water in the biofilter, the pressure drop analysis of SBC in comparison to compost was selected as the criteria to determine if materials were suitable to pack a biofilter. The comparative pressure drop study was performed as function of the main operational parameters that generally influence the process. Gas superficial velocity was increased up to $350 \mathrm{~m} \cdot \mathrm{h}^{-1}$ according to common operation conditions in biofilters (Devinny et al. 1999). The water content measured in each support material was achieved by continuously watering the material at different water velocities avoiding flooding episodes according to their own properties. Different porosities were obtained for compost packing the bed at different particle sizes and an only porosity of 0.93 for SBC due to its structure and shape.
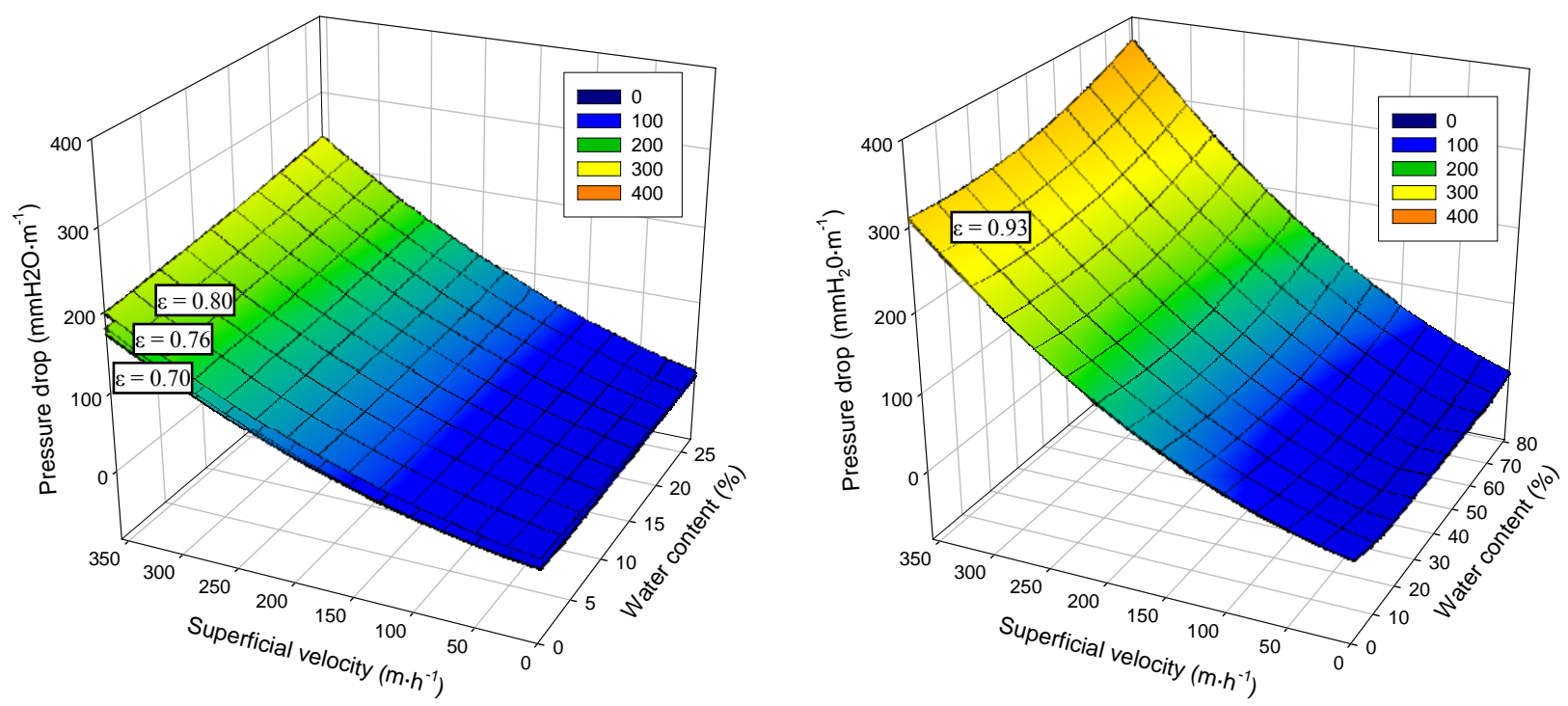

Figure 2. Influence of operational parameters on pressure drop for compost (a) and SBC (b). 
Results were represented in surface plots to observe simultaneously the influence of all parameters on pressure drop. Considering a wide range of conditions where materials are operative in a biofilter, pressure drop measured are sensitively higher in SBC than in compost which are in concordance with the shape and the specific surface area of materials. Results shown in figure 2 demonstrate that the pressure drop for SBC is more influenced by the gas flowrate than for compost even though the porosity of the bed for SBC is higher than for compost. Similarly, the water content influences SBC to a larger extent, even though the possible range of water content is also higher because in compost, the bed is flooded at water contents superior to $25 \%$ in bed volume due to the lower porosity of the bed. The strong dependence on water content is more important at high flow rates where the resistance to the flow towards the bed increases. Regarding to the porosity effect in compost, results do not show significant differences in the interval tested though three different sizes of particles were tested to achieve a wide range of operation.

\section{Behaviour of SBC in biofilter operation}

Once concluded that SBC shows an acceptable pressure drop in a wide range of operation conditions, the behaviour of material is analysed in an operative biofilter to treat toluene. Growth and immobilization of biomass on SBC were evaluated inoculating a lab-scale plant with activated sludge from a waste water treatment plant and studying the abatement of toluene in a reactor packed with the material mixed with coconut fiber $(1: 1, \mathrm{v}: \mathrm{v})$, which aided to held water content, during 80 days of operation (figure 3).

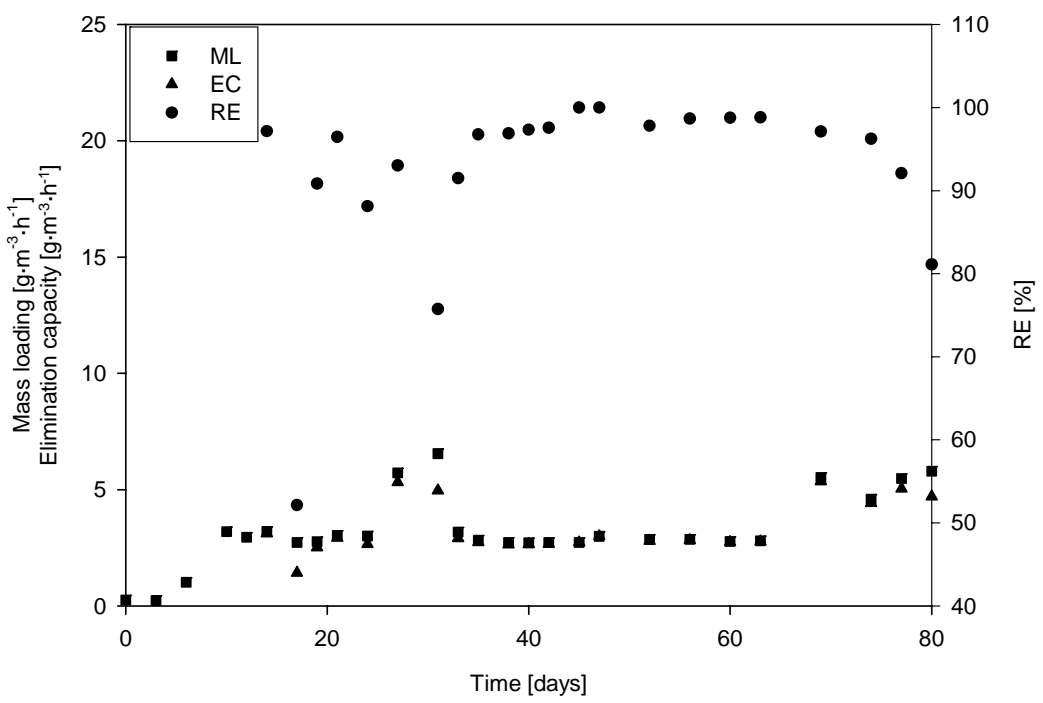

Figure 3. Toluene removal efficiency (RE), elimination capacity (EC) and mass loading (ML) using SBC as packing material in a lab-scale biofilter.

The gas flow rate was kept at $4251 \mathrm{~h}^{-1}$ (EBRT of $25 \mathrm{~s}$ ) meanwhile the toluene load ranged from 3 to $6 \mathrm{~g} \mathrm{~m}^{-3} \mathrm{~h}^{-1}$ of toluene. Operation and performance of the biofilter was reported in terms of toluene removal efficiency (RE) and elimination capacity (EC) (figure 3). First 10 days corresponds to the biofilters start-up phase, in which SBC was basically adsorbing toluene and the immobilized biomass was being acclimatised. Since day 14, nearly constant RE around 90\% was achieved, corresponding to an EC between 2.5 and $5 \mathrm{~g} \mathrm{~m}^{-3} \mathrm{~h}^{-1}$. Results demonstrate that physical characteristics of SBC, especially the high surface area and the high water holding capacity, were able to develop and maintain an active biomass on the surface of the material in a short time of acclimatization. In the first phase, while biomass was adapting to operation conditions, toluene was adsorbed on the material, before being metabolized, reducing the presence of pollutant at the outlet of the biofilter during this period. Moreover, nutrients content detected in SBC (table 1) could contribute to the growth and the maintenance of the biomass immobilized since the bed was 
watered with tap water without extra nutrients. On day 69 the toluene inlet load was increased from 3 to $5 \mathrm{~g} \mathrm{~m}^{-3} \mathrm{~h}^{-1}$ and RE was practically kept at $90 \%$ during the following days. According to the sorption capacity, the material is able to adsorb such load increase during an interval of time between 1 and 4 days depending on the degree of surface covered by water and biomass. Thus, results demonstrate some capacity of the biofilter packed with SBC to smooth inlet load changes. The high RE reported in the analysed operation time shows that SBC is an excellent support media to fix, grow and keep active the biomass responsible to degrade toluene as an example of abatement of a commonly VOC present in many gas waste flows.

\section{CONCLUSIONS}

The results obtained show the advantages and drawbacks of the use of SBC as packing material in biofiltration. The material produces cleaner leachate water, are able to provide extra nutrients to microorganisms, offer a high contact surface and a substantial sorption capacity in comparison to compost, which is the most suitable organic material pre-selected to pack a biofilter according to physical properties analysed. However, those parts of material covered with water in a normal operation of a biofilter lose an important part of the adsorption capacity, especially for hydrophobic pollutants. On the other hand, pressure drop is significantly higher than compost increasing the cost of operation. Nevertheless, results of the operation of a lab-scale biofilter using SBC as packing material demonstrate that material is a good support to immobilize and grow the biomass obtaining high removal efficiencies. Thus, taking the properties and the operation of a lab-scale biofilter packed with SBC into consideration, biofiltration is a useful application to dispose biological sludge from a wastewater treatment plant.

\section{ACKNOWLEDGEMENTS}

This work was supported by the Spanish CICYT project CTQ2006 - 14997-C02-02 and by the European Commission (REMOVALS project, Contract FP6-018525). A.D. Dorado received a predoctoral fellowship from the M.E.C. (Ministerio de Educación y Ciencia). Some physical analyses were performed by Serveis Cientificoténcics of Universitat de Barcelona and Universitat Autònoma de Barcelona.

\section{REFERENCES}

Alexander M. (1994). Biodegradation and bioremediaion. Academic Press, USA.

Bohn H.L. (1996). Biofilter media. Proceedings of the 89th annual meeting and exhibition of the air \& waste management association. Air \& Waste Management Association, USA.

Devinny J. S., Deshusses M.A. and Webster, T. S. (1999). Biofiltration for air pollution control. Lewis publishers, USA.

Do, D.D. (1998). Adsorption analysis: equilibria and kinetics. Imperial College Press, UK.

Janni K.A., Maier W. J., Kuehn T. H., Yang C.-H., Bridges B. B., Velsey D. and Nellis M. A. (2001). Evaluation of biofiltration of air-An innovative air pollution control technology. ASHRAE Transactions, 107, 198-214.

Kennes, C. and Thalasso, F. (2001). Bioreactors for waste gas treatment. Kluwer academic publishers, Netherlands.

Loy J., Heinrich K. and Egerer, B. (1997). Influence of filter material on the elimination rate in a biotrickling filter bed. Proceedings of the $90^{\text {th }}$ annual meeting exhibition of the air and waste management association. Air and waste management association, USA.

Pagans E., Font X. and Sanchez A. (2006) Adsorption, absorption, and biological degradation of ammonia in different biofilter organic media. Biotechnology and Bioengineering, 97 (3), 515 525.

Ruthven D.M. (1984). Principles of adsorption and adsorption processes. John Wiley \& Sons, Inc, USA.

TMECC (Test Methods for the Examination of Composting and Compost) (2002). The US composting council research an education foundation, and the US department of Agriculture. 
Vente J.A., Bosch H., Haan A.B. and Bussmann P. (2005). Evaluation of sugar sorption isotherm measurement by frontal analysis under industrial processing conditions. Journal of Chromatography A, 1066, 71-79.

Weber F.J., Hartmans S. (1995). Use of activated carbon as a buffer in biofiltration of waste gases with fluctuating concentrations of toluene. Appl.Microbial Biotechnol, 43, 365-369. 